\title{
The psychology of prosocial behavior: An introduction to a special issue
}

\author{
Manpal Singh Bhogal ${ }^{1}$ - Daniel Farrelly ${ }^{2}$ \\ Published online: 6 August 2019 \\ (C) Springer Science+Business Media, LLC, part of Springer Nature 2019
}

We are pleased to introduce our special issue for Current Psychology titled The Psychology of Prosocial Behavior. Researchers have long sought to empirically and philosophically explore why people are prosocial to others. Explanations have derived from a variety of disciplinary frameworks including economics, psychology, anthropology, biology, and philosophy. The collection of papers in this special issue showcase the diversity of approaches in psychology whereby people aim to understand prosocial behavior, ranging from evolutionary psychology to developmental psychology. We would like to thank Prof. Richard Ferraro, editor-in-chief of Current Psychology for supporting us in bringing you this special issue. He has provided an insightful editorial introduction to our special issue in Ferraro (2019). We would also like to thank the reviewers who took time out of their busy schedules to review the papers which were both accepted and rejected.

Researchers have long aimed to explore why people help others at a cost to oneself, which is helpful to the benefit of society. We observe prosociality in a variety of contexts, involving family, friends, co-workers, and strangers. Prosociality is also an umbrella term for a variety of forms of behavior including altruism (Farrelly 2019), cooperation (Bhogal, 2019), heroism (Margana et al. 2019), fairness (Bhogal et al. 2016, 2017), and trustworthiness (Ehlebracht et al. 2018). This signifies how powerful and varied prosociality is, and why it important to explore through an empirical lens. The diverse nature of the topic can also be seen in this special issue, where different authors have their own perception about what the term

Manpal Singh Bhogal

m.s.b2@wlv.ac.uk

Daniel Farrelly

d.farrelly@worc.ac.uk

1 Department of Psychology, University of Wolverhampton, Wolverhampton WV1 1LY, UK

2 School of Psychology, University of Worcester, St John's Campus, Henwick Grove, Worcester WR2 6AJ, UK prosociality means in their research. Essentially, the aim of bringing you this special issue is to bring together the variety of papers exploring the multidimensional phenomenon which is prosocial behavior.

This collection of papers includes empirical findings which strongly add to the literature on understanding prosocial behavior, including a narrative, critical literature review. The first paper by Marti-Vilar, Serrano-Pastor and González-Sala asks the question: what factors predict prosocial behavior? They propose an emotional intelligence model to explain prosociality, finding strong support. This paper shows that prosociality is multidimensional in nature. In the second paper, Stiff, Rosenthal-Stott, Wake and Woodward explore prosocial behavior in students during their time at university towards fellow students. In the third paper, Villar, Oceja, Salgado, Stocks and Carrera provide strong support for the relationship between Quixoteism and helping behavior, the first paper to explore this link.

In the fourth paper, Blakey, Mason, Cristea, McGuigan and Messer explored generosity in children, finding children's generosity depends on who they are engaging with, and that children strive for equality when distributing resources. In the fifth paper, Anli reports the validity and adaptation of the prosocial behavioral intentions scale, finding strong psychometric properties in a Turkish sample.

The following four papers adopt an evolutionary approach to understanding prosocial behavior, largely arguing, and finding evidence that prosocial behavior, predominantly altruistic behavior, is a mating signal. These papers provide further support that factors such as physical attractiveness influence prosocial behavior in a variety of contexts. In addition, people are attracted to altruistic mates as altruism is important in mate choice. These papers come from Schwartz and Baßfeld, and Norman and Fleming. Two of these papers include us, and our collaborators James Bartlett and Laura King.

Research by Balconi, Fronda, and Vanutelli offers an interesting view of how inter-brain connectivity is affected by giftgiving. This not only provides us with a neurological approach to prosociality, but also looks at both the giver and receiver in 
such exchanges. This is followed by research from Vermue, Meleady, and Seger on how prosocial behaviours in the form of trust (or a lack of it) can moderate how we perceive group members, which has important implications for real world interactions within and between different social groups in society. Gratitude as a prosocial behaviour is examined by Gulliford, Morgan, Hemming and Abbott, and they show that gratitude has the potential to mask manipulative and self-serving goals. This is a novel perspective on prosocial behavior, showing that prosociality can have a 'dark side'. Guan, Chen, Chen, Liu and Zha explore the phenomenon of awe and how it can promote prosociality within a Chinese population. They find a nuanced path between the two, which offers an interesting insight. An extreme form of applied prosociality, that of bone marrow donation, is the topic of research by Tuszyńska-Bogucka. This study looks at psychological predictors of donating behaviour and finds that there are complex and interesting determinants of people's decisions to be prosocial in this context.

The special issue ends with a critical review paper outlining the literature exploring prosocial behavior and mate choice, which we wrote with long-term collaborator Niall Galbraith. Finally, we thank the authors who submitted their papers for inclusion in our special issue. These well-designed and wellwritten papers have been written by authors at varying stages of their career, and we wish them success in their future endeavors.
We hope the readers of Current Psychology enjoy reading these papers as much as we have enjoyed editing them.

\section{References}

Bhogal, M. S., Galbraith, N., \& Manktelow, K. (2016). Physical attractiveness and altruism in two modified dictator games. Basic and Applied Social Psychology, 38(4), 212-222.

Bhogal, M. S., Galbraith, N., \& Manktelow, K. (2017). Physical attractiveness, altruism and cooperation in an ultimatum game. Current Psychology, 36(3), 549-555.

Bhogal, M. S. (2019). Altruism Advertises Cooperativeness. In: Shackelford T., Weekes-Shackelford V. (eds) Encyclopedia of Evolutionary Psychological Science. Springer, Cham.

Ferraro, R. F. (2019). Special Issue on Psychology of Prosocial Behavior. Current Psychology. https://doi.org/10.1007/s12144-019-00336-4.

Ehlebracht, D., Stavrova, O., Fetchenhauer, D., \& Farrelly, D. (2018). The synergistic effect of prosociality and physical attractiveness on mate desirability. British Journal of Psychology, 109(3), 517-537.

Farrelly, D. (2019). Indirect Benefits of Altruism. In: Shackelford T., Weekes-Shackelford V. (eds) Encyclopedia of Evolutionary Psychological Science. Springer, Cham.

Margana, L., Bhogal, M. S., Bartlett, J. E., \& Farrelly, D. (2019). The roles of heroism, altruism, and physical attractiveness in female mate choice. Personality and Individual Differences, 137, 126-130.

Publisher's note Springer Nature remains neutral with regard to jurisdictional claims in published maps and institutional affiliations. 